\title{
ОСОБЕННОСТИ ОРГАНИЗАЦИИ ВНУТРЕННЕГО АУДИТА В РЕГИОНАЛЬНЫХ УПРАВЛЕНИЯХ БЮДЖЕТНЫХ УЧРЕЖДЕНИЙ
}

\author{
(c) 2019 Нагимова Ирина Альбертовна \\ кандидат экономических наук, доцент, \\ кафедра «Финансы, денежное обращение и экономическая безопасность» \\ Уфимский государственный авиационно-технический университет, Республика Башкортостан, Уфа \\ E-mail: inagimova@list.ru
}

\section{(c) 2019 Шерышева Анастасия Николаевна}

кандидат экономических наук, доцент,

кафедра «Финансы, денежное обращение и экономическая безопасность»

Уфимский государственный авиационно-технический университет, Республика Башкортостан, Уфа

E-mail: a.sherysheva@yandex.ru

\section{(C) 2019 Мендель Олеся Петровна}

старший преподаватель, кафедра «Финансы, денежное обращение и экономическая безопасность» Уфимский государственный авиационно-технический университет, Республика Башкортостан, Уфа

E-mail:mop82@mail.ru

\section{(c) 2019 Комарова Екатерина Сергеевна}

старший преподаватель, кафедра «Финансы, денежное обращение и экономическая безопасность» Уфимский государственный авиационно-технический университет, Республика Башкортостан, Уфа

E-mail: katy02@mail.ru

В условиях рыночной экономики усиливаются задачи по повышению рентабельности и текущего контроля деятельности организаций. Множество организаций страдают от неэффективности использования ресурсов - людских, финансовых, материальных, от недостатка необходимой для принятия правильных решений информации, непреднамеренного и преднамеренного искажения отчетности со стороны персонала и управляющих. Подобные проблемы можно разрешить путем должной организации внутреннего аудита. В этой связи внедрение внутреннего аудита и оценка его эффективности в организации, а также разработка методик проведения внутреннего аудита является актуальной.

В статье раскрыты роль и значение внутреннего аудита в бюджетных учреждениях, обоснована необходимость введения внутреннего аудитора в штат регионального подразделения бюджетного учреждения, предложены методики проведения внутреннего аудита.

Ключевые слова: внутренний аудит, методика аудита, бюджетное учреждение, оценка рисков, внутренний аудитор, должностные инструкции, финансовый контроль, бюджетный контроль

В настоящее время актуальной задачей является оценка рисков и прогнозирование состояния предприятия с точки зрения выполнения свойственных ему функций, принятия мер их защиты от воздействия различных внутренних и внешних факторов. При этом в современных условиях предприятию важно не избегать риска, а предвидеть его, одновременно стремясь снизить его до минимально допустимого уровня. Для этого необходим постоянный, действенный и своевременный контроль над деятельностью компании в целом, её подразделений и сотрудников.
Одним из наиболее действенных инструментов, позволяющих выявить возможности повышения эффективности бизнеса, его конкурентоспособности и устойчивого развития и, следовательно, одним из инструментов обеспечения экономической и финансовой эффективности компании может стать система внутреннего аудита [3].

Если рассматривать бюджетные учреждения, то система внутреннего контроля, частью которого является внутренний аудит, в них имеет свои особенности. Функции внутреннего контроля и внутреннего аудита в бюджетных уч- 
реждениях представлены в таблице 1.

Региональные управления бюджетных организаций охватывают широкий объем функций, связанных с обеспечением государственного контроля и надзора за деятельностью подведомственных организаций, с лицензированием подконтрольных видов деятельности, проведением аттестации лиц, занимающих должности исполнительных руководителей и специалистов, контроль за проведением государственных закупок в подведомственных организациях, а также иные функции в сфере контроля.

Региональные управления бюджетных учреждений находятся на бюджетном финансировании и, как правило, обладают небольшим кадровым составом, при этом организации необходимо осуществлять активный поиск эффективного использования финансовых ресурсов с целью рационального распределения расходов. С другой стороны, создание собственной службы внутреннего аудита, а не привлечение независимых аудиторов, наиболее целесообразно с целью обеспечения экономической и информационной безопасности как управления, так и всего региона по данному направлению в целом. В связи с чем необходимо рассмотреть введение в управлениях должности внутреннего аудитора, в структуре управления в непосредственном подчинении руководителю управления, но подотчетного головной организации - главному распорядителю бюджетных средств.

Внутренний аудитор должен осуществлять операционный аудит и финансовый аудит. Так, операционный аудит, направлен на оценку экономности, и на эффективное расходование государственных средств. Финансовый аудит, направлен на содействие организации в обеспечении правильности ведения бухгалтерского учета, законности использования бюджетных средств, достоверной финансовой отчетности и организации действенного финансового контроля, и внутреннего контроля закупок.

При введении должности внутреннего аудитора необходимо выполнить следующие мероприятия:

1. Разработка положения о службе внутреннего аудита.

Миссия внутреннего аудита заключается в оказании необходимого содействия руководству Управления и руководству Федеральной службы в выполнении их обязанностей по достижению целей, поставленных государством перед ними.

Служба внутреннего аудита должна выполнять все задачи, поставленные перед ней.

Внутренний аудит осуществляется службой в целях:

- обеспечения эффективности и рациональности в распределение бюджетных средств;

- обеспечения достоверности, полноты, объективности и своевременности составления и предоставления бухгалтерской отчетности;

- обеспечения соблюдения законодательства Российской Федерации, бюджетного кодекса, нормативных правовых актов;

- обеспечения последующего контроля в сфере закупок.

Внутренний аудитор должен руководствоваться следующими нормативно-правовыми актами:

- Международными стандартами внутреннего аудита;

- Федеральным законом «Об аудиторской

Таблица 1. Внутренний финансовый аудит и контроль в бюджетных учреждениях

\begin{tabular}{|c|c|c|c|}
\hline \multicolumn{3}{|c|}{ Внутренний финансовый контроль } & $\begin{array}{c}\text { Внутренний финансовый } \\
\text { аудит }\end{array}$ \\
\hline $\begin{array}{c}\text { Главный распорядитель } \\
\text { бюджетных средств } \\
\text { (ГРБС) }\end{array}$ & $\begin{array}{c}\text { Главный администратор } \\
\text { доходов (ГАД) }\end{array}$ & $\begin{array}{c}\text { Главный администратор } \\
\text { источников финансиро- } \\
\text { вания (ГАИФ) }\end{array}$ & ГРБС, ГАД, ГАИФ \\
\hline $\begin{array}{l}\text { Контроль направлен на: } \\
\text { 1) соблюдение вну- } \\
\text { тренних стандартов и } \\
\text { процедур составления и } \\
\text { исполнения бюджета по } \\
\text { расходам; } \\
\text { 2) осуществления мер по } \\
\text { повышению результатив- } \\
\text { ности и эффективности } \\
\text { использования бюджет- } \\
\text { ных средств. }\end{array}$ & $\begin{array}{l}\text { Контроль за соблюдением } \\
\text { внутренних стандартов } \\
\text { и процедур составления } \\
\text { и исполнения бюджета } \\
\text { по доходам, составления } \\
\text { бюджетной отчетности и } \\
\text { ведения бухгалтерского } \\
\text { учета. }\end{array}$ & $\begin{array}{l}\text { Контроль за соблюдением } \\
\text { внутренних стандартов и } \\
\text { процедур составления и } \\
\text { исполнения бюджета по } \\
\text { источникам финансиро- } \\
\text { вания дефицита бюджета. }\end{array}$ & $\begin{array}{l}\text { Аудит в целях: } \\
\text { 1) выражения мнения о } \\
\text { надежности внутреннего } \\
\text { финансового контроля; } \\
\text { 2) подтверждения до- } \\
\text { стоверности бюджетной } \\
\text { отчетности; } \\
\text { 3) подготовки предложе- } \\
\text { ний по повышению ре- } \\
\text { зультативности и эффек- } \\
\text { тивности использования } \\
\text { бюджетных средств. }\end{array}$ \\
\hline
\end{tabular}


деятельности» от 30 декабря 2008 г. № 307-ФЗ.

Применять в своей деятельности внутренний аудитор обязан следующие нормативно-правовые акты:

- Федеральный закон от 6 декабря 2011 года № 402-Ф3 «О бухгалтерском учете»;

- Бюджетный кодекс Российской Федерации;

- Приказ Минфина России от 08.06.2018 $\mathrm{N} 132 \mathrm{H}$ «О Порядке формирования и применения кодов бюджетной классификации Российской Федерации, их структуре и принципах назначения».

Принципами организации и деятельности службы внутреннего аудита, в том числе определяющими ее статус, являются:

- постоянство деятельности;

- независимость и беспрепятственное осуществление службой внутреннего аудита своих функций;

- беспристрастность;

- профессиональная компетентность сотрудника службы внутреннего аудита.

2. Разработка должностных обязанностей внутреннего аудитора и ознакомление сотрудника под роспись.

В административном регламенте должны быть прописаны следующие полномочия:

- беспрепятственный доступ к любым документам, бухгалтерским, налоговым и управленческим записям, доступ в помещения проверяемого подразделения;

- доступ к операционным системам, электронным базам данным иным носителям информации;

- изъятие оригиналов документов, в случае если при осуществлении внутреннего контроля будут обнаружены подделки, подлоги иные злоупотребления.

Основной обязанностью службы внутреннего аудита является осуществление проверок финансовой деятельности и проведения государственных закупок.

Внутренний аудитор несет ответственность 3a:

- соблюдение конфиденциальности информации и документов, получаемых или используемых им в своей деятельности;

- систематизацию и обеспечение сохранности документального фонда аудита;

- полноту, достоверность и объективность информации, предоставляемой подразделени- ям и руководству управления при выполнении функций внутреннего контроля;

- соблюдение установленных правил внутреннего трудового распорядка.

Претендент на должность внутреннего аудитора должен пройти обучение по внутреннему аудиту, по государственным закупкам (знание Федерального закона 44-Ф3 «О контрактной системе в сфере закупок товаров, работ, услуг для обеспечения государственных и муниципальных нужд») и по противодействию коррупции.

Оценка работы, проделанной аудитором, будет происходить с помощью использования ключевых показателей эффективности (KPI). Выделим следующие показатели, по которым будет происходить оценка работы аудитора в управлении:

- снижение стоимости закупок (в \%);

- экономия расходов (в \%);

- процент выполнения плана проверок (отношение фактически выполненных за период аудиторских проверок к запланированному количеству);

- проведение за период проверок в расчете на одного сотрудника службы внутреннего аудита;

- отсутствие нарушений при внешних проверках (в \%).

Чем ближе к единице показатель, тем лучше. Если показатель ближе к нулю, то работа сотрудника считается неэффективной. Данная оценка будет происходить ежемесячно, так как от этого зависит заработная плата.

3. Определение Кодекса этики.

Кодекс этики внутреннего аудитора является обязательным документом для определения этических принципов сотрудника.

4. Разработка положения по регулированию взаимодействия внутреннего аудитора с другими подразделениями.

Внутренний аудитор взаимодействует с финансово-хозяйственными подразделениями с целью получения информации и документов для проверки.

5. Ежегодное составление плана проверок.

Планы работ разрабатываются внутренним аудитором и утверждаются руководством управления. План проведения проверок, осуществляемых службой внутреннего аудита, должен включать график осуществления проверок.

При составлении графика осуществления проверок должна учитываться установленная в 
управлении периодичность проведения проверок в финансово-хозяйственном подразделении. План проверки должен быть реалистичным, т.е. должен включать запас времени для выполнения других задач и другой деятельности, таких, как внеплановые проверки, вынесение заключений, обучение и прочее.

Акты проверок должны представляться руководству вышестоящей надзорной организации, руководству Управления на регулярной основе, но не реже двух раз в год. Отчеты должны содержать описание целей проверки, выполненных работ, выявленных нарушений, ошибок и недостатков в финансовой деятельности и основной деятельности, которые могут создать угрозы для управления или оказать влияние на эффективное распределение бюджетных средств. Помимо этого, должна составляться записка с рекомендациями внутреннего аудитора по улучшению работы и устранению нарушений, ошибок и недостатков.

Масштаб аудита осуществляется в соответствии с объемом проверок, следовательно, будет определяться соответствующий план, а также с увеличением рисков будет увеличиваться количество проверок. Один раз в три месяца должны проверяться расходы и доходы, государственные закупки.

Взаимоотношения внутреннего аудитора с сотрудниками и руководством Управления должны строиться таким образом, чтобы объективность и беспристрастность их выводов не могла быть подвергнута сомнению. Внутренний аудитор не может участвовать в какой-либо деятельности, которая могла бы повлиять на объективность его оценок и выводов, а также использовать полученную информацию в личных интересах или каким-либо образом, способным нанести ущерб интересам управления.

6. Внутренний аудитор должен проводить мониторинги ключевых проблемных моментов таких как:

- планирование госзакупок;

- порядок ведения бюджетного учета;
- исполнение бюджета по расходам и доходам.

7. Внутреннему аудитору необходимо осуществлять оперативное решение проблем по запросам руководства, а также проблем, выявленных в процессе проверки бухгалтерской отчетности и мониторинга госзакупок.

Для эффективного управления рисками, оценку рисков управления рекомендуется производить путем составления карты рисков периодичностью один раз в квартал. Оценка рисков возможна с помощью качественного анализа, осуществляемого с помощью методик оценки степени риска и вероятности наступления рисковой ситуации. Диапазон вероятности составляет значение от 0 до 1 и делится на три группы:

- от 0 до 0,2 - наступление риска маловероятно;

- от 0,21 до 0,65 - наступление риска вероятно;

- свыше 0,65 - наступление риска весьма вероятно.

Таким образом, по результатам оценки можно составить карту рисков, форма приведена в таблице 2 .

Для проведения количественного анализа внутреннему аудитору необходимо использовать методы PEST-анализа - инструмент, предназначенный для выявления политических (Political), экономических (Economic), социальных (Social) и технологических (Technological) аспектов внешней среды, которые влияют на организацию. Анализ рекомендуется выполнять по схеме «фактор-предприятие». Результаты анализа оформляются в виде матрицы, подлежащим которой являются факторы макросреды, сказуемым - сила их влияния, оцениваемая в баллах, рангах и других единицах измерения.

Результаты PEST-анализа позволят оценить внешнюю экономическую ситуацию, складывающуюся в сфере производства и коммерческой деятельности.

Систематически внутренний аудитор должен осуществлять оценку эффективности систе-

Таблица 2. Карта рисков Управления

\begin{tabular}{|c|c|c|c|c|c|c|}
\hline \multirow{2}{*}{$\begin{array}{c}\text { Описание } \\
\text { риска }\end{array}$} & \multicolumn{3}{|c|}{ Вероятность возникновения риска } & \multicolumn{3}{c|}{ Степень опасности потерь } \\
\cline { 2 - 7 } & Маловероятно & Вероятно & $\begin{array}{c}\text { Весьма веро- } \\
\text { ятно }\end{array}$ & Неопасный & Допустимый & Опасный \\
\hline 1 & 2 & 3 & 4 & 5 & 6 & 7 \\
\hline \multicolumn{7}{|c|}{ Внутренние риски } \\
\hline \multicolumn{7}{|c|}{ Внешние риски } \\
\hline
\end{tabular}


Таблица 3. Анкета тестов проверки состояния внутреннего контроля

\begin{tabular}{|c|c|c|}
\hline $\begin{array}{c}\text { Содержание вопроса или объекта } \\
\text { исследования }\end{array}$ & Содержание ответа & Оценка риска \\
\hline $\begin{array}{l}\text { Проводится ли проверка своевременности } \\
\text { утверждения сметы? }\end{array}$ & $\begin{array}{l}\text { Нет, так как производится несистематиче- } \\
\text { ская проверка контрольными органами }\end{array}$ & низкий \\
\hline $\begin{array}{l}\text { Проводится ли проверка своевременности } \\
\text { перечисления в доход «сумма возврата де- } \\
\text { биторской задолженности прошлых лет»? }\end{array}$ & $\begin{array}{l}\text { Нет, так как контроль за дебиторской за- } \\
\text { долженностью Управлением не ведется на } \\
\text { постоянной основе }\end{array}$ & высокий \\
\hline $\begin{array}{l}\text { Проводится ли проверка своевременности } \\
\text { и полноты осуществления платежей по до- } \\
\text { ходам от сумм принудительного взыскания } \\
\text { штрафов? }\end{array}$ & $\begin{array}{l}\text { Да, так как контроль ведется Управлением } \\
\text { систематически }\end{array}$ & низкий \\
\hline $\begin{array}{l}\text { Проводится ли проверка своевременности } \\
\text { внесения изменений в бюджетную смету? }\end{array}$ & $\begin{array}{l}\text { Да, так как контроль проводится руководи- } \\
\text { телем Управления систематически }\end{array}$ & низкий \\
\hline $\begin{array}{l}\text { Проводится ли проверка правильности ис- } \\
\text { числения, полноты и своевременности осу- } \\
\text { ществления платежей по прочим доходам? }\end{array}$ & $\begin{array}{l}\text { Нет, в Управлении нет проверки по данному } \\
\text { направлению }\end{array}$ & высокий \\
\hline
\end{tabular}

мы внутреннего контроля при помощи тестирования. Для этого предлагается использовать анкетирование. Пример составления анкеты представлен в таблице 3.

На основании результатов тестирования системы внутреннего контроля внутренний аудитор сможет более точно спланировать работу, необходимые аудиторские процедуры и сможет определить степень надежности информации, на основании которых сможет подготовить необходимые рекомендации руководству Управления в вопросе построения системы внутрен- него контроля.

Кроме этого, могут быть применены и другие методы аудита: аудит расходов, аудит расчетов по заработной плате, аудит операций с основными средствами. Как правило это проблемные сферы деятельности региональных управлений.

Внедренные методики должны увеличить эффективность управления расходами организации, позволить выявить основные риски регионального управления и построить стратегию деятельности бюджетного учреждения в целом.

\section{Библиографический список}

1. олесник А.Л. Методика внутреннего аудита казенного учреждения. Учет. Анализ. Аудит. № 1. 2017. С. 47-54.

2. Методические рекомендации по осуществлению внутреннего финансового контроля. Электронный ресурс: https://www.minfin.ru/common/upload/library/2017/07/main/_ Metodicheskie_rekomendatsii_po_organizats_ upravleniya_riskami_i_VK.pdf

3. Нагимова И.А., Надриина Л.А. Служба внутреннего аудита как инструмент обеспечения экономической безопасности предприятия. Сборник материалов конференции. Экономическая безопасность: концепция, стандарты. Изд. УГАТУ. 2016. С. 113-117.

4. Приказ Минтруда России от 24.06.2015 № 398н «Об утверждении профессионального стандарта «Внутренний аудитор» [Электронный ресурс].- Режим доступа: http://www.fa.ru/fil/ufa/dpo. 